\author{
Published by Avanti Publishers
}

The Global Environmental

Engineers

ISSN (online): 2410-3624

\title{
Assessing the Economic Feasibility of Integrated Waste to Use Systems for Uganda
}

\author{
Miria Frances Agunyo ${ }^{1, *}$, Sarah Kizza-Nkambwe ${ }^{1}$ and Kukunda Elizabeth Bacwayo ${ }^{2}$ \\ ${ }^{1}$ Department of Engineering \& Environment, Faculty of Engineering, Design and Technology, Uganda Christian University, \\ Uganda. \\ ${ }^{2}$ School of Research and Post Graduate Studies, Uganda Christian University, Uganda
}

\section{ARTICLE INFO}

Article Type: Research Article

Keywords:

Payback Period

Net Present Value

Internal Rate of Return

Economic Feasibility Assessment

Integrated Waste to Use Systems

Timeline:

Received: September 08, 2021

Accepted: November 15, 2021

Published: November 08, 2021

Citation: Agunyo MF, Kizza-Nkambwe S, Bacwayo KE. Assessing the Economic Feasibility of Integrated Waste to Use Systems for Uganda. Glob. Environ. Eng. 2021; 8: 27-45.

DOl: https://doi.org/10.15377/2410-3624.2021.08.3

\begin{abstract}
Waste and sanitation Management is a major challenge in urban areas in Uganda where waste is composed of atleast $70 \%$ organic content and is basically collected and disposed of in landfills. While $90 \%$ of the sanitation facilities used are onsite systems often requiring additional treatment of sewage and faecal matter sewage yet faecal and sewage sludge treatment plants are few. The projected population increase is expected to further influence urbanization, increasing the need for basic waste and sanitation services. Integrated Waste to Use systems that consider combined management of organic waste streams i.e. biowaste, animal waste, sewage and faecal sludge, could be a viable solution for the urban areas. The systems which consist of a combination of anaerobic digestion, composting, incineration and solar drying technologies promote resource recovery in the form of biogas, briquettes and organic fertilizer. The economic feasibility of the Waste to Use systems was carried out and the results indicated that the feasibility of the systems was positively influenced by the inclusion of the anaerobic digestion process, which allowed for recovery of biogas and digestate as organic fertilizer. Furthermore, a combination of low system investment costs, increased revenues from resource recovery, consideration of equity capital of at least 30\%, interest rate of at most $10 \%$ and fugitive emissions less than $7 \%$ would positively influence the economic feasibility of the system alternatives.
\end{abstract}

*Corresponding Author

Email: anomotmiria@gmail.com, magunyo@ucu.ac.ug Tel: +256782514800

(c) 2021 Agunyo et al. Published by Avanti Publishers. This is an open access article licensed under the terms of the Creative Commons Attribution Non-Commercial License which permits unrestricted, non-commercial use, distribution and reproduction in any medium, provided the work is properly cited. (http://creativecommons.org/licenses/by-nc/4.0/) 


\section{Introduction}

In Sub-Saharan Africa, waste management is still a major challenge, especially in urban areas. City, municipal or town authorities are often mandated to ensure waste management and yet these authorities are often constrained by a lack of relevant financial resources, technical expertise and may experience competition for the existing relevant regulatory framework to support the management of solid waste, lack of awareness amongst the citizens and weak enforcement of existing regulation, make managing waste in these countries an uphill task. Often, the general trend in waste management includes the collection of waste from different locations and disposal at landfills or dumpsites [1]. A similar trend exists in Uganda where management of waste is the mandate of the urban authorities that are constrained by similar challenges. Management mechanism adopted mainly consists of a collection of comingled waste from various source points and disposal at landfills. Studies show that atleast $70 \%$ of the waste disposed at the landfills in the urban areas is organic in nature implying that negative environmental impacts due to emission of greenhouse gases and leachate which pollute the environment and cause other health and livelihood related impacts result may result [2-4].

In terms of sanitation management in the urban areas of Uganda, atleast $90 \%$ of the population use onsite sanitation facilities consisting mainly of pit latrines, pour-flush toilet and septic tank systems and yet the country has a sewerage coverage of only about $2 \%$ and less than 30 centralized faecal sludge treatment plants to help further treat the sewerage and faecal sludge generated from the onsite sanitary facilities. This exposes the challenges experienced in sanitation management as well [5-7].

Uganda's annual rate of urbanization is currently $5.2 \%$ and projections show that at least 56 million inhabitants will reside in urban areas by 2050, implying that the challenges currently experienced in waste and sanitation management could be exacerbated. This is because in most cases the necessary infrastructural development may not be at per with the firstly growing demand for services [6-8].

With such a background, Integrated approaches to managing the various waste streams are crucial given the fact that urbanization will increase and that in addition to putting a strain on the existing infrastructure, competition for resources like land for landfilling is getting high. Already for cities like Kampala, the existing landfill Kiteezi is full and plans are underway to initiate the use of Ddundu land which was procured by the Authority as the next landfill. Ddundu landfill located in Kiryamuli and Buntaba Villages in Mukono District is about 45km away from Kampala City Centre [4,9]. Meanwhile for other cities and urban areas within the country like Mbale, Masaka, Mbarara, a similar trend can be traced, where the landfills are getting filled up and the 'panic' to search for alternative sites by the local authorities is met with the competition for land by other land uses, making the purchase of alternative landfills an expensive venture [10,11].

Taking into consideration these challenges, different integrated management approaches including recycling and resource recovery from solid waste have been practiced at different levels in the country. Nationally, the National Environment Management Authority (NEMA) with financing support from the World Bank provided capital investment for the establishment of composting plants in 12 municipalities. This initiative is aimed at reducing GHG emissions to the environment resulting from the decomposition of organic waste while improving solid waste management and protecting water catchments from pollution. Despite the implementation of this project with the first installation being operational by 2010 in Jinja City, findings indicate that most of the composting facilities are no longer operational, mainly due to limited financial resources to facilitate activities. Also, the breakdown of equipment has affected various processes at the composting plants [3].

Meanwhile, in most of the urban areas, many entities at the individual and company level are involved formally and informally in waste management especially, recycling of the waste with others focusing on recovering plastic, scrap metal and other resources. The involvement of the private sector as both micro and small enterprises/registered companies in the recycling of waste is mostly informal, fragmented and at times illegally carried out, making it difficult to obtain the necessary financing to support their initiatives and receive technical guidance $[12,13]$. The fragmented approach in waste and sanitation management currently undertaken in most urban areas of the country makes it difficult to ensure quality control, enforcement, hold responsible entities to 
account and properly documents lessons learned. It is against this background that the authors are interested in assessing the feasibility of integrated Waste to Use systems for application in specific contexts or entities with similar challenges.

The integrated systems proposed in this study consider a holistic approach to managing organic residues, particularly integration of sanitation and organic solid waste management. The integrated system concept is not new since it is based on the environmental sanitation approach which focuses on the management of human excreta, solid waste and wastewater, drainage as well as vector control among others [14-17].

The proposed integrated waste to use systems approach considers combined management of organic waste streams such as sewage and faecal sludge, animal waste, biowaste and wastewater effluent. Key system components/technologies considered include anaerobic digestion, composting, incineration and solar drying. As such, the systems have two main objectives i.e. management of organic waste streams and resource recovery from waste.

The integrated waste to use systems proposed in this paper are not necessarily new since some practical examples exist where management of organic solid waste and wastewater has been carried out at wastewater treatment plants (WWTPs) in developed countries. Adopting such an approach in some cities has enhanced the treatment and management of a significant percentage of organic waste streams that would otherwise end up in landfills $[15,19]$. In developing countries like Uganda, the application of Waste to Use systems can be seen in solid waste management, where a 3R approach based on the reduce, reuse and recycle principle is promoted. Also, treatment and management of wastewater and solid organic waste using Eco-San and Bio-latrine systems have been adopted [1,20]. Despite the application of Waste to Use systems, especially in developing countries, the maturity of the approach can be considered to be limited since few installations are have been made at the domestic and maybe institutional level and there is little documented evidence of the applications.

As such, one of the objectives of this study was to propose Waste to Use system alternatives that could be applicable for various entities such as housing estates, institutions, towns/cities etc. The design of the different Waste to Use system alternatives later discussed in Section 3 was informed by some of the already existing applications within the country and the need for additional interventions with regards to sanitation and waste management.

Also, a set of criteria was considered for application of the proposed Waste to Use systems and this entailed (i) location in urban areas, (ii) availability of demand for environmental sanitation services with a focus on the management of organic waste streams, (iii) service demand population should be at least 1,000 people and that (iv) engagement amongst various stakeholders is expected given that there are various players along with the waste management and resource recovery value chain.

Cognizant of the benefits the integrated Waste to Use system approach offers i.e. resource recovery and management of sanitation, assessing the economic feasibility of such systems becomes crucial given that application to a broader scope i.e. institutions, estates cities/towns is envisioned. Such an assessment would contribute to the discussion on the sustainability of the systems given that the environmental and social-cultural assessments of the systems proposed indicate that these systems are feasible [21,22]. It is envisioned that this study will further inform future adoption of the system alternatives which could promote the achievement of numerous sustainable development goals i.e. SDG 6 clean water and sanitation, 7 affordable and clean energy and SDG 11 on sustainable cities and communities.

Thus, the second objective of this study was to assess the economic feasibility of integrated Waste to Use systems using the cost-benefit analysis method. The economic feasibility assessment creates a link between the anticipated impacts and the economic returns as a result of the improved sanitation intervention. As already mentioned, limited examples of the integrated Waste to Use systems exist locally [23,24]. Moreover, for the case of Uganda, the few documented economic feasibility studies carried out in the sector highlight the costs incurred due to poor sanitation but do not necessarily assess the feasibility of specific systems, making this study relevant to the body of knowledge. 


\section{Materials and Methods}

In this study, an explanatory research design is adopted to explore the concept of Integrated Waste to Use systems for urban areas in Uganda. Moreover, a case study approach is further used to inform the explanatory research design following the use of cost-benefit analysis as a method of assessing the systems.

\subsection{Case Study Area}

In this study, Uganda Christian University (UCU), Mukono was considered the case study area. As is the case for most private institutions/entities, in Uganda, UCU is mandated to manage waste generated from the facility. The private University has its own activated wastewater treatment plant (WWTP), which treats wastewater from various source points within the University before disposing of the sewage sludge to lagoons within the plant for further stabilization. Currently, the WWTP treats $160 \mathrm{~m}^{3} /$ day and is operating at half its capacity. Meanwhile, other waste such as plastic generated at the University is sorted and recycled while bio-waste from kitchen waste is used as animal feed by local farmers neighboring the University.

The remaining waste which is mostly hazardous and inorganic in nature is either incinerated at UCU or disposed of at Mukono Municipal landfill, located about $7 \mathrm{~km}$ from the University campus. Noteworthy is that the University experiences difficulty in the final disposal of sewage sludge since only partial stabilization can be achieved in the open lagoons. The current practice is that about $70 \%$ of the partially stabilized sewage sludge is left in lagoons while $30 \%$ is used as a soil conditioner on the University's sports field and by interested local farmers' within Mukono Municipality. Furthermore, the University heavily depends on firewood for cooking, accounting for about $90 \%$ of cooking demand and yet the University's management is interested in adopting the use of clean fuels to meet her cooking demand as indicated in her strategy.

Taking into consideration the sanitation needs in Mukono Municipality, there is no centralized WWTP or faecal sludge treatment plant or connection to the National Water and Sewage Corporation (NWSC) sewer network in the area. Despite the absence of these infrastructures, the Municipality also depends on onsite pour flush toilets connected to septic tanks and pit latrines as the main sanitary facilities [34]. For such facilities, further treatment and management of sewage and faecal sludge is often required. This implies that those in need of the services have to bear the cost of hiring cesspool emptiers to transport the sludge to faecal sludge management plants such as Lubigi and Bugolobi located in Kampala, $22 \mathrm{~km}$ away from Mukono. With such a challenge at hand, the WWTP at UCU which operates at half its capacity could be considered for further treatment of sewage sludge from neighboring areas of Mukono if appropriate measures are taken into consideration.

With the challenges experienced in the management of organic waste streams such as bio-waste, sewage and faecal sludge both at UCU and in the neighboring areas of Mukono Municipality, in addition to the need to substitute firewood with clean energy fuels like biogas to meet cooking demand, the integrated waste to use systems could be a viable solution. Moreover, to boost biogas production in the waste to use systems proposed in this study, alternative substrates such as cow dung from the University farm was considered as potential additional feedstock for the systems.

Following the state criteria for consideration, UCU registered a population of up to 10,000 people, the demand to manage organic waste streams such as sewage sludge, bio-waste exits, the University is located in Mukono Municipality which is an urban area and given that an opportunity to further treat sewage and or faecal sludge from neighboring Mukono exists, various stakeholders including farmers interested in using organic fertilizer could benefit from the application of the systems.

The integrated waste to use systems proposed for UCU would treat the organic waste streams from the University and neighboring environs such as sewage and faecal sludge, animal excreta, 'bio-waste and wastewater effluent. Treatment of these waste streams while recovering resources such as biogas, compost, organic fertilizer and briquettes were considered in designing the systems. The designs of the systems considered a combination of anaerobic digestion technologies and other technologies/process units such as incineration, composting and solar drying among others. As such, six system alternatives were proposed and compared in this 
study and a description of the design and components of the system alternatives is handled in section 3.

To inform the economic assessment of the waste to use systems considered in this study, reference to other studies of sanitation systems/interventions as carried out. For the most part, assessment of sanitation intervention or projects, attempt to link impacts of poor sanitation to economic losses while concurrently assessing economic returns associated with reducing the burden of health and negative impact on the environment. Thus, negative impacts associated with people 's/citizens' lost time and their loss in productivity due to poor health as well as environmental impacts from the related interventions or projects are often considered for such assessments [25-27]. Common practice indicates that when the economic assessment of sanitation system alternatives is carried out, incorporation of life cycle costs and benefits is often considered [26,28,29]. As such, the authors follow a similar approach in this paper, where, costs and benefits of the integrated Waste to Use system alternatives are assessed. Using the cost-benefit analysis (CBA) method for the economic assessment of the system alternatives, computation of parameters such as the net present value (NPV), payback period (PBP) and internal rate of return (IRR) was considered so that a more comprehensive assessment is carried out

As such, computation of the system, component installation and operation costs was considered. Also, computation of economic returns associated with reducing environmental impacts and the burden on health due to the use of the Waste to Use systems was considered. Computation of these economic returns was based on the assessment of citizens' time recovered and increased productivity due to having improved Waste to Use systems in place $[26,27]$. In addition, returns associated with resource recovery expected from the management of the various organic waste streams was additionally computed, giving a holistic approach to the economic assessment.

The three parameters that defined the economic feasibility assessment were as; the NPV which is the sum of all cash flows discounted for the given duration and computed according to the Equation 1.

$$
N P V=\sum_{t=1}^{T} \frac{C_{t}}{(1+r)^{t}}-C_{o}
$$

Equation 1

Where NPV is the net present value of the Integrated Waste to Use system (s), $\mathbf{C}_{\mathbf{t}}$, the cash flow of the investment for the duration $\mathbf{t}, \mathbf{C}_{\mathbf{0}}$ is the initial investment for the system, $\mathbf{r}$ is the discount rate in (\%), $\mathbf{t}$ is the time period from the first year to $\mathbf{T}$ years.

The IRR is the discount rate when the after-tax $\mathbf{N P V}$ is zero and is computed according to Equation 2.

$$
0=\sum_{t=1}^{T} C_{t}(1+I R R)^{-t}-C_{0}
$$

Equation 2

Where IRR is the internal rate of return of the system (s), $\mathbf{C}_{\mathbf{t}}$ is the cash flow of the investment for the duration $\mathbf{t}, \mathbf{C}_{\mathbf{0}}$ is the initial investment for the waste to use the system, $\mathbf{t}$ is the time period from the first year to $\mathbf{T}$ years.

Finally, the PBP is used to compare revenues with costs and determine the duration required to recoup the initial investment and is computed according to Equation 3.

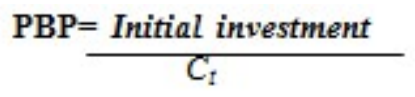

Equation 3

Where $C_{t}$ is the cash flow of the investment in time period $t(s)$ and PBP is the payback period [30,31].

In this paper, a full appreciation of the economic assessment of the integrated waste to use systems using the CBA was achieved by considering a case study approach, which allowed for an empirical inquiry that investigated the phenomenon of the Waste to Use systems within a real-life context [32]. 


\section{Results}

As already mentioned, six waste to use systems were designed and considered for the comparative economic assessment. The designs of the system alternatives were informed by the needs assessment of the cases study area and neighboring environment, taking into consideration the existing conditions at UCU. Description of the system alternatives is carried out in the following section.

\subsection{System Alternatives}

The Status Quo alternative represented the current system of sanitation management at UCU with a few modifications taken into consideration i.e. inclusion of pump for the sewage sludge from the WWTP to a settling tank, prior to partial stabilization of the sewage sludge in the lagoons. Furthermore, utilization of food waste (Fw) from the kitchen as animal feed for local farmers and application of cow dung (Cd) from the University farm in gardens as a soil conditioner was taken into consideration.

Combination of composting and anaerobic digestion (COMPAD) system design considered separate management of the sewage sludge from the WWTP by directing it to the lagoons where partial stabilization and dewatering would take place prior to composting of the sludge with other organic waste. Specifically, the other organic waste considered was wood shavings from carpentry and a portion of kitchen waste which would be added to boost the organic content and quality of compost produced. This would then be used as a soil conditioner. Meanwhile, the system is also considered an anaerobic digestion unit where cow dung (Cd) and food waste (Fw) in the ratios Cd:Fw (50:50) as main substrates. To ensure optimal production of biogas from the digester, pre-treatment of food waste from the kitchen was considered in addition to mixing it with cow dung prior to anaerobic co-digestion in a continuous stirred tank reactor (CSTR), operating under mesophilic conditions $\left(30-42^{\circ} \mathrm{C}\right)$. Biogas produced from the digester would then be utilization with reference to two scenarios was i.e. direct utilization of the biogas as a cooking fuel (BfC) or for cogeneration (CoGen) to produce electricity and heat from a Combined Heat and Power (CHP) unit.

The CHP design specifications considered included at least $50 \mathrm{~kW}$ power rating with an overall efficiency of 83\% i.e. an electricity conversion of $31 \%$ and heat output of $52 \%$. Additionally, utilization of digestants produced from the anaerobic digestion process as organic fertilizer was also considered. Thus, resources recovered from this system i.e. electricity and heat from biogas and organic fertilizer were considered to substitute electricity from the national grid, thermal energy generated from firewood for cooking at UCU and mineral fertilizers used by local farmers in the Mukono area. This system alternative was designed also bearing in mind application by entities that also had provision of land to allow for the installation of composting unit such as institutions and also housing estates etc.

Combination of anaerobic digestion and composting at Mukono -Landfill (COMPAD LF). This integrated waste to use system design considered similar units to the COMPAD alternative with the exception that composting of sewage sludge and organic waste would be carried out at Mukono Municipality landfill instead of at UCU campus. This variation was considered in the design because the landfill at Mukono already has a composting unit installed. As such, additional design considerations to cater for transportation of the inputs to the landfill located about $7 \mathrm{~km}$ away from the University campus were incorporated instead of incurring additional costs for installing a composting unit at UCU. Meanwhile, an anaerobic digestion unit was still incorporated into the system design. This anaerobic digestion unit would be located at UCU and handling of biogas and digestate would be as described for the COMPAD system. This system alternative was considered ideal for urban areas such as towns, cities etc. where composting units were already available and a collaborative approach to managing the various waste streams is factored in.

Combination of incineration and anaerobic digestion (INCAD). This integrated waste to use system design consisted of similar components to the COMPAD alternative although additionally solar drying of the partially stabilized sewage sludge from the lagoon to reduce the moisture content prior to co-incineration with other waste, taking into consideration recovery of energy in form of waste heat. 
Meanwhile, anaerobic digestion of substrates such as cow dung and food waste were still considered. Byproducts such as biogas and digestate from the anaerobic digestion unit would be handled in a similar manner to the COMPAD and COMPAD LF systems. This stem alternative was also considered ideal for entities such as hospitals, health facilities institutional facilities as well as well-planned housing settlements where incinerators exist, allowing for management of other hazardous waste streams while recovering resources. Figure 1 gives an overview of key processes informing the designs of the three integrated waste to use system alternatives described.

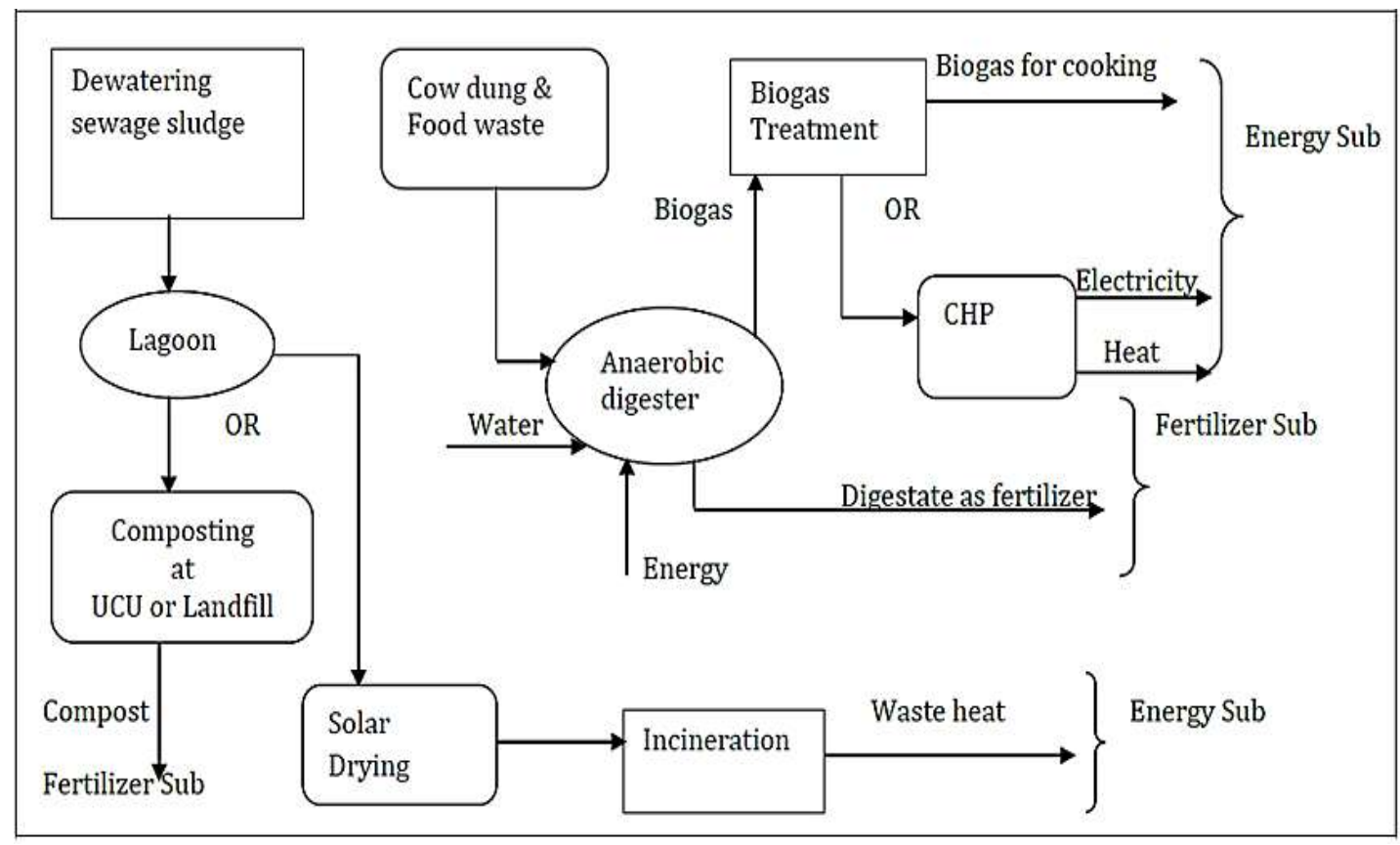

Figure 1: Overview of COMPAD, COMPAD LF, INCAD waste to use system components.

Two additional integrated waste to use systems were designed taking into consideration additional organic waste streams as described.

The integrated (INTEG 1) system design $r$ incorporated mixing sewage sludge (Os) from the WWTP with other substrates such as food waste(Fw), cow dung(Cd) according to composition ratios (Os: Cd: Fw 30:20:50). Moreover, effluent from the WWTP would be used as process water for mixing the substrates. The substrate mixture would then be anaerobically digested, producing biogas and digestate. Biogas produced would be managed in a similar manner described for COMPAD, COMPAD LF and INCAD systems. Meanwhile, digestate from the digester was directed to the lagoons where partial stabilization and dewatering would take place before it is solar-dried to improve the quality of the organic fertilizer produced given that sewage sludge was used as one of the substrates. This systems alternative was designed bearing in mind entities such as cities, institutions like UCU where sewage sludge in addition to other organic waste streams are generated and require further treatment.

The integrated 2 (INTEG 2) system was also designed similar to the INTEG 1 alternative but additionally considered faecal sludge (Fs) as one of the substrates anaerobically digested. Thus, a substrate mixture of the composition Fs:Os:Cd:Fw 10:20:20:50 was considered. Additional design considerations included 40\% of the solardried digestate used for briquette production, while the remnant $60 \%$ be used as organic fertilizer. As such, additional substitution of firewood with briquettes made from digestate and other organic waste such as sawdust was considered. As initially stated, for all the system alternatives where anaerobic digestion unit was incorporated in the design, two scenarios i.e. utilization of biogas as a cooking fuel (BfC) or for cogeneration (CoGen), producing electricity and waste heat were taken into account. Additional uses of the heat generated from the CoGen scenario were for heating the digester to ensure mesophilic conditions are maintained and heating water utilized for cooking purposes in the kitchen. 


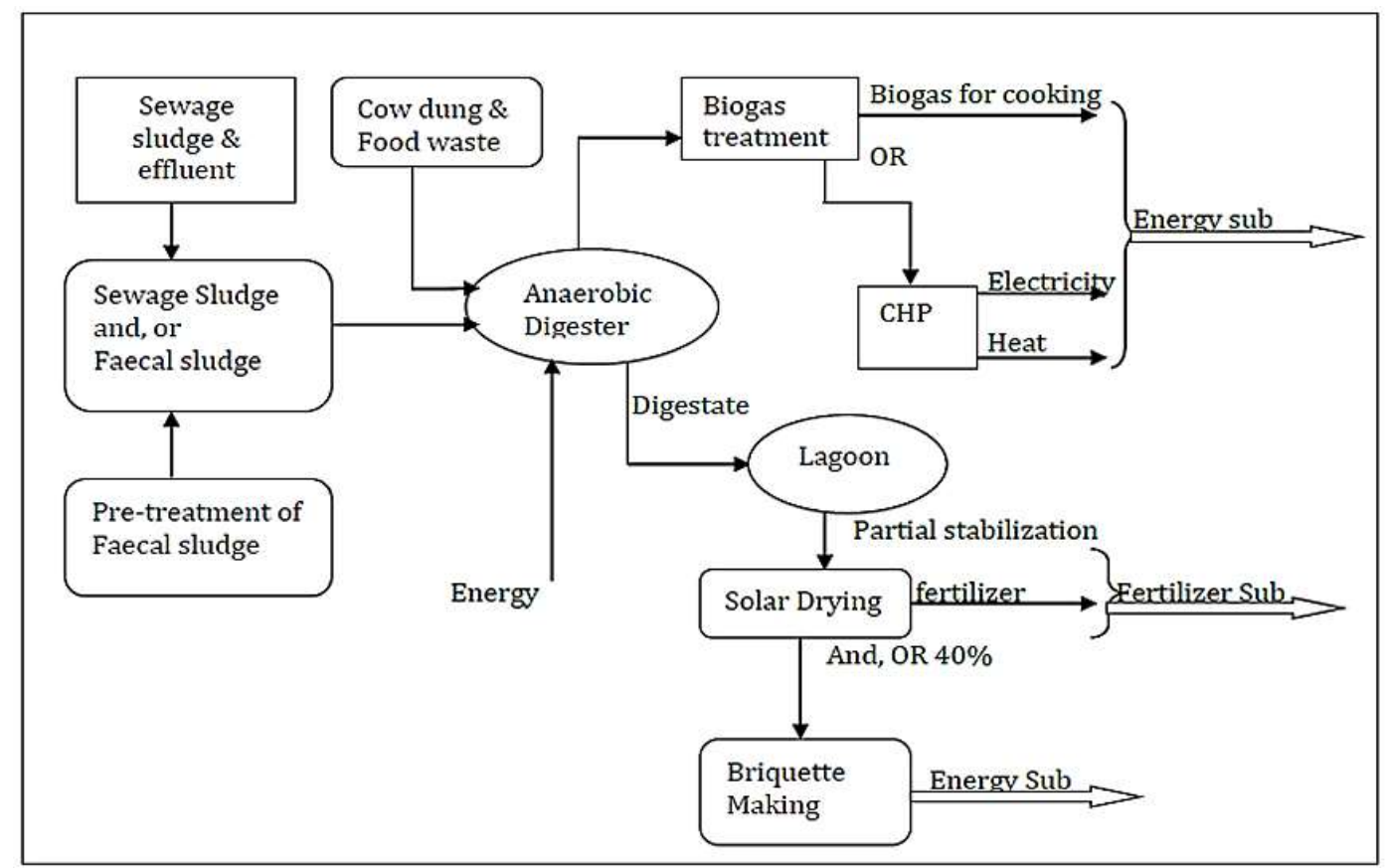

Figure 2: Overview of INTEG 1 and INTEG 2 waste to use system components.

The INTEG 2 systems alternative was designed to cater for entities where additional treatment of faecal sludge would be required like in cities, towns, institutions as well as housing estates etc. Figure $\mathbf{2}$ gives an overview of key processes proposed within INTEG 1 and 2 waste to use system alternatives described.

Thus, to enable comparative assessment of integrated Waste to Use system alternatives designed, a framework for the economic assessment was developed and this included evaluation of the costs and benefits of the respective systems as discussed in the following sections.

\subsection{Data Sources}

In this study, the data used for the economic assessment of the integrated energy and resource recovery system alternatives were obtained from literature, key informants and through site visits enhanced by observation in various parts of Uganda. Additional data related to anaerobic digestion for the various system alternatives were obtained through experimental analysis, where characterization of the organic waste streams to determine the total solid and volatile solid content of the substrates was carried out as shown in Table 1.

Table 1: Substrate/Feedstock information.

\begin{tabular}{|c|c|c|c|}
\hline Substrate/Feedstock Type & Input Tons/year & TS \% & 52.30 \\
\hline \hline Food waste & 202.23 & 36.69 & 27.66 \\
\hline Cow dung & 208.53 & 10.56 & 7.81 \\
\hline Sewage Sludge & 486.68 & 8.52 & 6.30 \\
\hline Faecal sludge & 243.34 & & \\
\hline
\end{tabular}

Source: Authors.

To obtain the methane yield of the substrates from UCU, the Biomethane Potential experiment was setup based on the Maritte displacement principle for quantifying the amount of methane produced [45,48]. Fig. 3 shows the methane yield for the respective substrates obtained from UCU. 


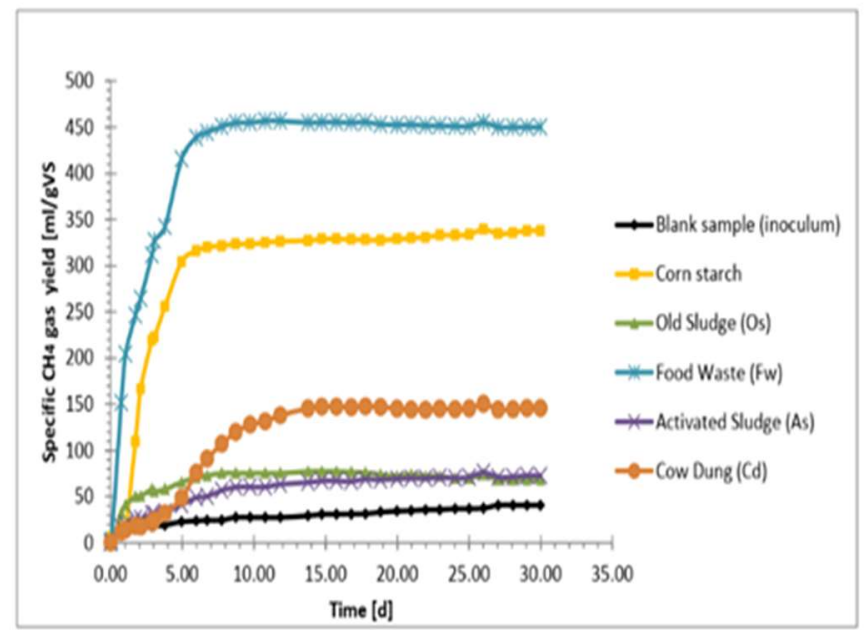

Figure 3: Methane yield for substrates from UCU.

The results obtained from the experiments carried out were further referred to an assessment for the respective system alternatives, taking into consideration the substrate compositions.

Also, reference to literature related to the economic feasibility of biogas plants and sanitation systems informed cost estimation for the proposed system components considered [35-37]. Reference was made to the designs proposed and defined for each system alternative to further inform cost and benefit estimation. Specifically, benefits for each of the system alternatives accrued from resource recovery in the form of biogas, digestate considered as organic fertilizer and briquettes were computed. In addition, environmental benefits associated with a reduction in greenhouse gases (GHGs) and health benefits related to improved sanitation from the respective system alternatives were also considered in the assessment $[38,39]$. Specifically, the environmental benefits were attributed to the recovery of biogas from the anaerobic digestion process, averting the emission of GHG i.e. methane and carbondioxide to environment. While the computation of the health benefits associated with each of the integrated waste to use system alternatives was informed by literature. Here, reference was made to literature that suggests that waterborne and sanitation-related diseases consist mainly of infectious diarrhea, which is considered the cause of the main global burden resulting from poor access to water supply and sanitation. Moreover, the availability of regional and national data on diarrhea incidence rates and deaths also informed investigations of the health benefits associated with the systems interventions resulting in a reduction in diarrhea incidence $[29,4041]$. In this paper the economic benefits associated with improved sanitation services from the systems were assessed based on three key areas;

- Savings from seeking less health care to treat diarrhea diseases associated with poor sanitation. Health care savings were estimated as a function of treatment-seeking rates, medical practices and unit costs for medical services required.

- Savings related to productive time losses when one is sick from diarrheal related disease. Here, productivity losses were estimated based on disease rate prevalence in addition to the number of days a patient or caretaker could be absent from productive activities and the unit value of productive time.

- Also, savings related to reductions in premature mortality of persons affected with the diarrheal disease were considered. Mortality was valued using the human capital approach, where estimation of the value of a premature death averted due to improved sanitation associated with the systems was taken into consideration.

As initially mentioned, benefits in form of revenue from the potential sale of digestate either as organic fertilizer or as cooking fuel (briquettes) were also computed. These computations were supported by studies that show that digested sludge has a high content of nutrients, primarily nitrogen and phosphorus, justifying the use of treated sewage as a potential fertilizer source and soil conditioner $[42,43]$. 
The authors also considered the fact that anaerobic digestion technology mainly allows for the treatment of sewage sludge to some extent, resulting in partial stabilization and degradation of biological contaminants such as pathogens and weed seeds. Often the case, degradation of physical contaminants i.e. pieces of inert or larger pieces of digestible material and chemical contaminants like heavy metals or complex organic pollutants may not occur in the anaerobic digester. This extent of treatment exposes a gap with regards to the quality of digestate eventually considered as soil conditioner/fertilizer, highlighting the need for additional treatment measures for substrates such as sewage sludge prior to anaerobic digestion. In line with this, the authors carried out preliminary quality tests to determine the nutrient and heavy metal content in the sewage sludge obtained from UCU. Reference was made to European Commission standards for heavy metal content in sewage sludge in the even it is used as a biosolid/soil conditioner [44,45]. Table 2 below shows the heavy metal and nutrient content obtained in the UCU sewage sample at the laboratory.

Table 2: Heavy metal and nutrient content of sewage sludge sample from UCU.

\begin{tabular}{|c|c|c|}
\hline Parameter & Mean Values UCU Sewage Sample & EC Ceiling Concentration Limits for all Biosolids Applied on Land* \\
\hline \hline Cadmium(mg/Kg) & $<0.001$ & $20-40$ \\
\hline Copper(mg/Kg) & 7.501 & $1000-1750$ \\
\hline Nickel & $<0.001$ & $300-400$ \\
\hline Lead(mg/Kg) & $<0.001$ & $750-1200$ \\
\hline Zinc(mg/Kg) & 29.107 & $2,500-4,000$ \\
\hline Potassium(mg/Kg) & 47.398 & \\
\hline Total Nitrogen(mg/Kg) & 2.260 & \\
\hline Phosphorus $(\mathrm{mg} / \mathrm{Kg})$ & 4.900 & \\
\hline
\end{tabular}

Source: Government Laboratory, Uganda.

The results indicated that sewage sludge from UCU had negligible heavy metal concentration while significant amounts of nutrients were obtained, justifying utilization of the digestate as soil conditioner/fertilizer. The preliminary assessments become relevant especially when substrates such as sewage sludge from other sources i.e. hospitals, industrial establishments etc. are considered since this will help inform improvement in the design considerations of the systems. Incorporating additional treatment provisions to cater for further use and or management of the digestate is crucial $[44,45]$. In the event that there is a significant composition of heavy metals in the sewage sludge then, other processes can be considered in the design. Thermal treatment of the anaerobically digested sewage using, incineration or pyrolysis processes have been known to fix the heavy metals in the ash or char prior to final disposal $[46,47]$.

\subsection{CBA Method Adopted}

To enable the economic assessment of the integrated waste to use systems proposed for UCU, a Microsoft Excel-based tool was developed by the authors. The tool consisted of sections to compute available substrate quantities for the biogas digester, which eventually informed the estimation of the annual biogas amounts from the system alternatives (refer to Table 2).

Also, computation of costs (capital and operational) and benefits for all system alternatives was carried out. This included the examination of how implementation and operation of key components of the system alternatives would be achieved. Thus, estimation of the initial investment costs for the integrated waste to use systems was carried out. These estimations were informed by literature and supplier information for the various design components for the system alternatives [35,36,49-51]. Meanwhile, estimation of the operation costs comprised of net operating costs, maintenance costs, requirements for financing and insurance costs for each of the system alternatives.

Computation of the benefits for the respective system alternatives additionally factored in associated 
environmental and health benefits as already discussed. The total discounted costs and revenues/benefits were then applied in the computation of the NPV, IRR, PBP and a sensitivity analysis was carried out to appreciate the robustness of the assumptions and results obtained.

\subsubsection{Main Assumptions Considered}

The following key assumptions informed computations;

- Equity capital for each for the systems compared was assumed to be $30 \%$ of the investment costs.

- Fugitive emissions from the biogas plant/anaerobic digestion unit accounted for $7 \%$ of the biogas amount generated.

- An interest rate of $10 \%$ was used and this was based on key informant interviews from GIZ -Uganda and Uganda Energy Credit Capitalization Company (UECCC).

- While the loan payback period was assumed to be 10 years.

For all integrated waste to use system alternatives consisting of an anaerobic digestion unit, two scenarios were considered i.e.; utilization of biogas directly for cooking (BfC) and utilization of biogas for cogeneration (CoGen). Figure $\mathbf{4}$ shows an overview of the procedure adapted for the assessment of the economic feasibility of the system alternatives proposed for UCU.

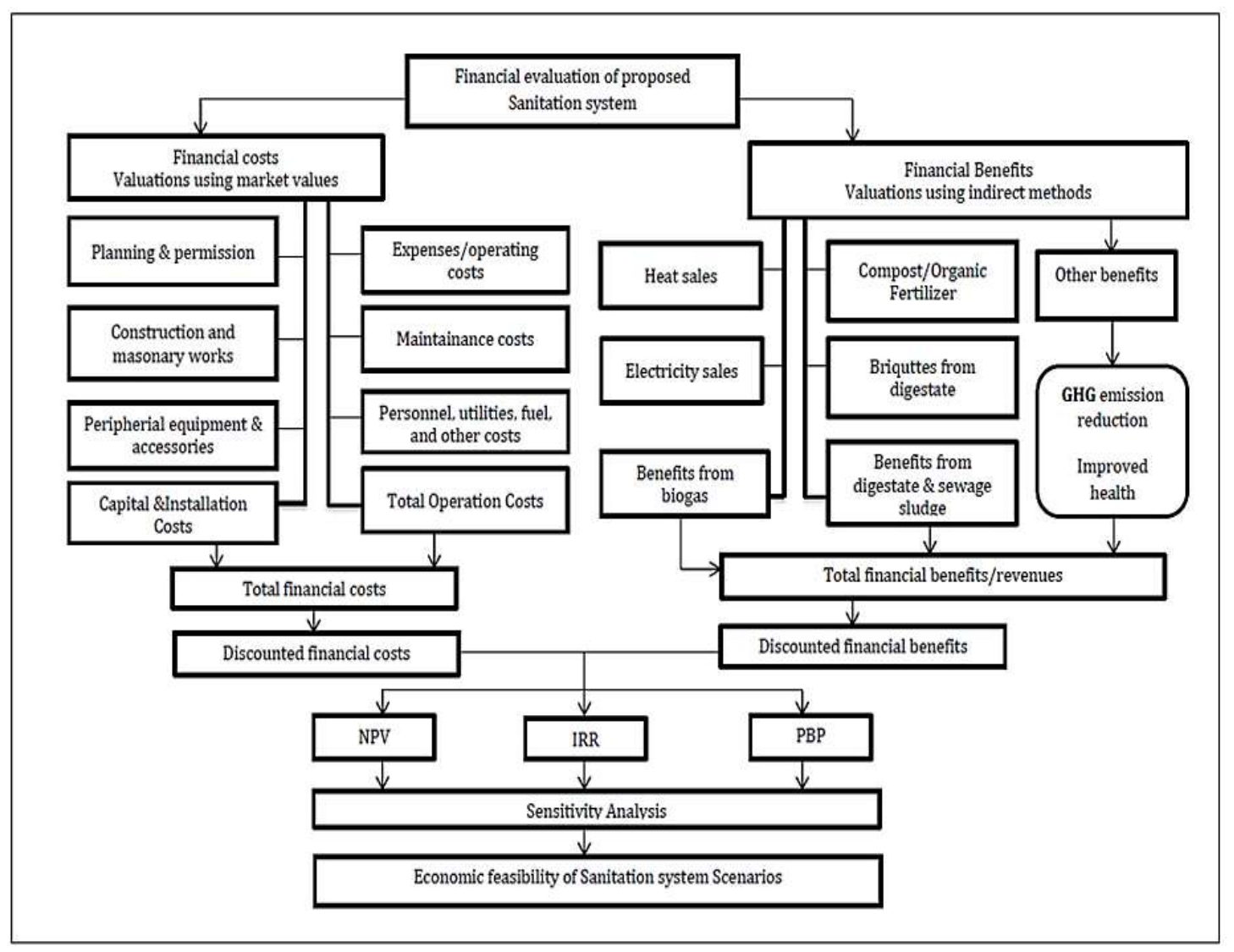

Figure 4. Framework for the economic feasibility assessment.

\subsection{Discussion of Results}

Following the framework proposed for the assessment included in Fig. 4, comparison of the performance of the six waste to use systems was carried out. Results indicated that, taking into consideration the CoGen scenario (generation of electricity and heat from biogas), the NPV of INTEG 2 system was the highest with atleast 931 
million UGX followed by COMPAD LF, INTEG 1, COMPAD, INCAD while the least NPV was registered for the Status Quo system alternative since resource recovery was limited to mainly use of the sewage sludge as a soil conditioner. Fig. 5. Shows the performance of the system alternatives with regards to NPV.

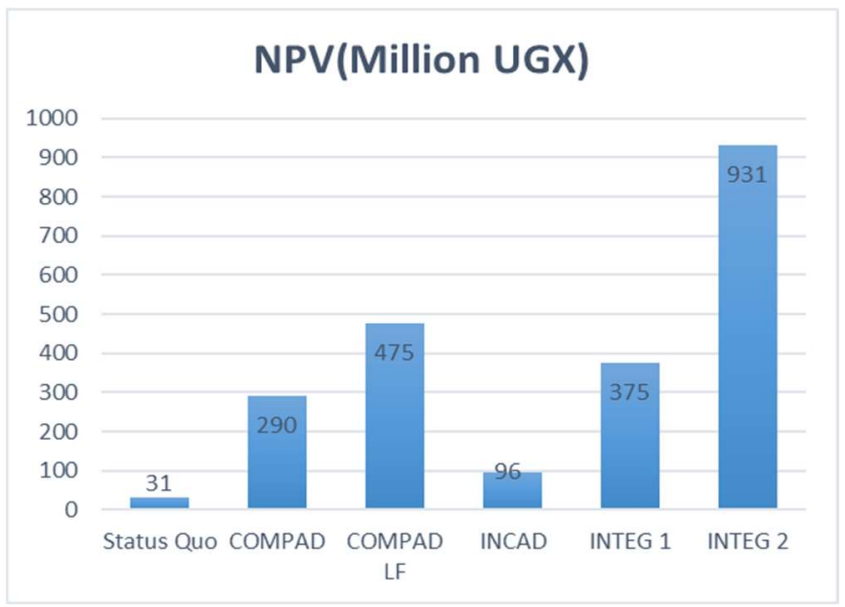

Figure 5: NPV of all waste to use system alternatives.

For systems like the INTEG 2 that had higher annual income, this was attributed to the additional byproducts such as briquettes, electricity, heat and organic fertilizer. While, the good performance of other system alternatives i.e. COMPAD LF, INTEG 1 and COMPAD was also attributed to the byproducts considered i.e. organic fertilizer, electricity and heat although the variation was associated with the investment required in terms of the system components. The COMPAD LF system considered the use of an already installed composting unit at the landfill in Katikoolo while, for the INTEG 1 and COMPAD systems installation of components at the University was considered. For all systems, environmental benefits associated with recovery of biogas and use for energy recovery were also a bonus.

With regards to the PBP and IRR, the performance trend showed that the Status Quo alternative performed best with a PBP of only 1.3 years and IRR of 79\% followed by the COMPAD LF, INTEG 2, INTEG 1, COMPAD and finally the INCAD alternative as shown in Fig. $\mathbf{6}$.

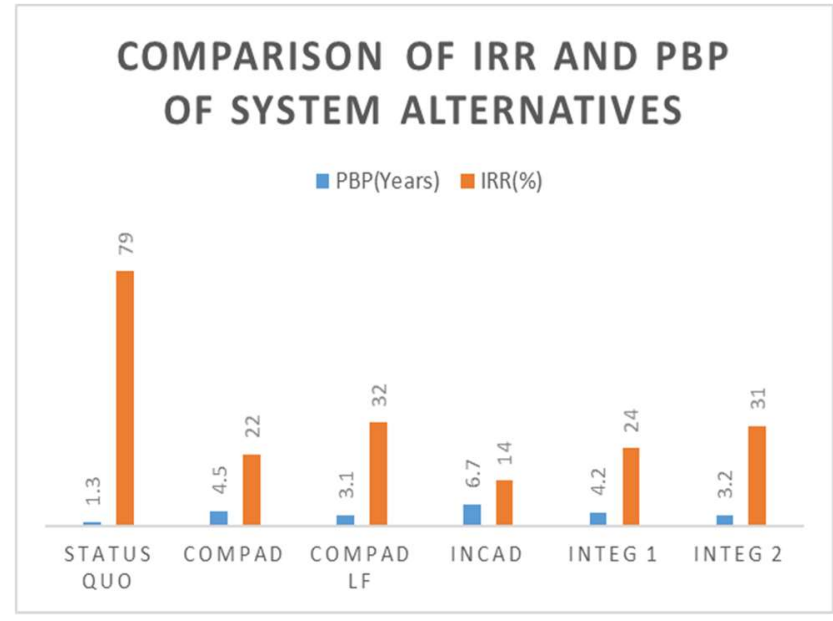

Figure 6: IRR and PBP for COGEN system alternatives.

Worthy of mention is that for all system alternatives, a PBP registered was less than the 10-year loan period. Meanwhile, with reference to the IRR, the Status Quo alternative registered at least $79 \%$, while the remaining system alternatives registered IRR values ranging between 14-32\%. The good performance of the Status Quo alternative with reference to these two parameters was because the main design considerations for the Status 
Quo system consisted of modifications to existing structures at UCU i.e incorporate a roofing structure for the lagoons at the wastewater treatment plant, while the rest of the infrastructure already existed, implying that the overall investment costs were much lower than for the rest of the system alternatives.

In terms of benefits, the system accrued an income due to health improvement associated with the system. As such, the Status Quo alternative performed significantly better than the remaining system alternatives which had significantly higher installation costs for the respective system components. On further scrutiny, the much better performance of the COMPAD LF systems alternative in comparison to the INTEG 2, INTEG 1, COMPAD, and INCAD alternatives was also attributed to the fact that the alternative had reduced investment costs since an existing composting plant unit at Mukono was considered in its design. Thus, taking into consideration all three parameters i.e. NPV, IRR and PBP, the performance trend showed that COMPAD performed best followed by INTEG 2 then Status Quo, INTEG 1, COMPAD and finally INCAD.

When the utilization of biogas for cooking (BfC) scenario was considered, all the waste to use system alternatives except for the INCAD alternative registered positive NPVs. The performance trend with regards to NPV still showed that the INTEG 2 alternative was the best performer with an NPV of atleast UGX 549 million, followed by the COMPAD LF, with UGX 266 million, the INTEG 1 with UGX 98million, COMPAD and the Status Quo and finally the INCAD alternative, with a negative NPV as shown in Fig. $\mathbf{7 .}$

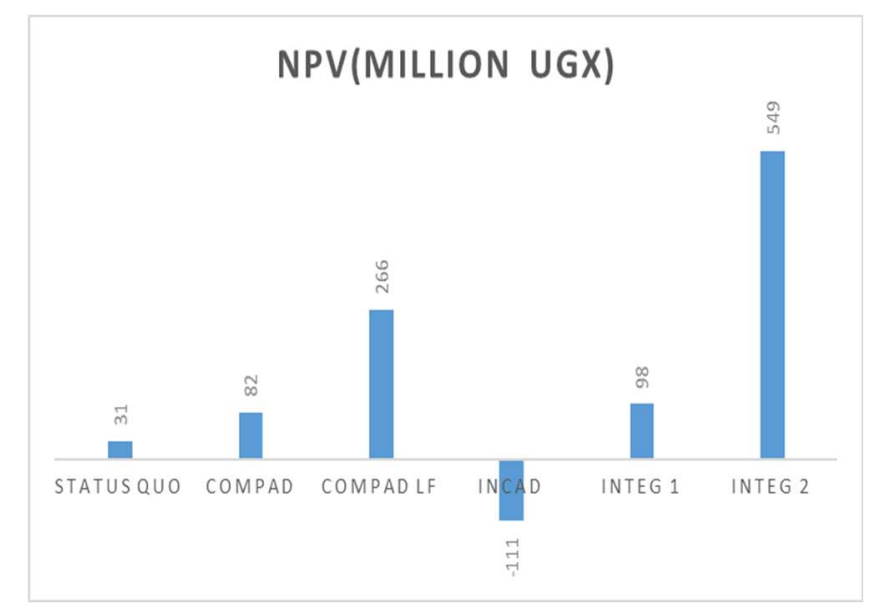

Figure 7: NPV for system alternatives BfC scenario.

Similar to the CoGen scenario, the performance of the system alternatives was positively influenced by the annual income accrued from the sale of by-products for the respective system alternatives. Thus, the higher the annual income, the better the system alternative performed. Meanwhile, the negative NPV registered for the INCAD system alternative was attributed to the much lower income accrued of about 22 million UGX in comparison to the overall cost of investment for the system of about 304 million UGX. Given that sewage sludge was considered incinerated in the INCAD alternative, the only by-products recovered were biogas for cooking and the organic fertilizer or soil conditioner from the anaerobic digestion unit. As such, the overall annual income from the system alternatives was lower than costs when compared to other alternatives.

Meanwhile, when the PBP and IRR parameters were considered, the performance trend for the systems showed that the Status Quo alternative still performed best and there was a slight variation with the INTEG 2 alternative performing better than the COMPAD LF alternative. Thus, the trend showed Status Quo with performed best with an IRR of 79\% and PBP of 1.3 years, followed by INTEG 2, COMPAD LF, INTEG 1, COMPAD and finally INCAD with a PBP of 13.4 years as shown in the Fig. $\mathbf{8 .}$

A similar explanation holds with the performance of system alternatives hinged on additional revenue accrued from the sale of by-products for systems such as the INTEG 2, and reduced investment costs especially for system alternatives such as the Status Quo and COMPAD LF. 


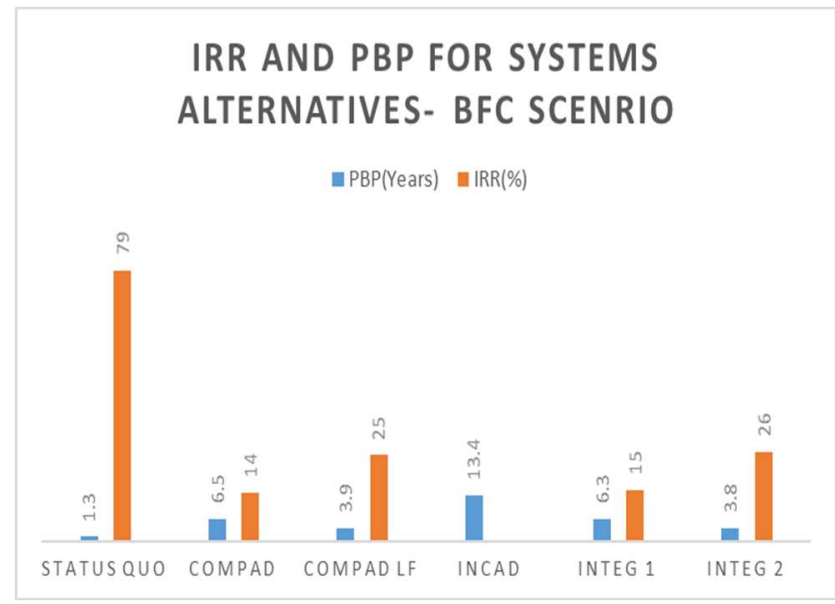

Figure 8: IRR and PBP for system alternatives-BfC scenario.

The overall performance trend with reference to all three parameters for the BfC scenario showed that INTEG 2 was the best alternative followed by the Status Quo, COMPADLF, INTEG1 then COMPAD and finally INCAD. When the overall results for the two scenarios were considered for all system alternatives, higher NPV, lower PBP and higher IRR values were registered when CoGen scenario was considered in comparison to when BfC scenario was considered. These results suggested that taking into consideration the cogeneration of biogas to produce electricity and heat (CoGen) could be economically more attractive in comparison to utilizing the biogas for cooking (BfC).

However, it should be noted that such a consideration can only be based on the priorities of the responsible entity, in this case, UCU. Thus, the institutions preference would be crucial in deciding whether or not the biogas produced is used to meet the direct cooking demand, replacing firewood and charcoal use or generation of electricity from the biogas for other purposes including meeting cooking demand. Moreover, in the event, similar system designs are considered for other entities such as health centers, towns cities etc. a similar stance would be considered i.e. the preference/ priority of the entity with regards to how the biogas produced is utilized. Table $\mathbf{3}$ gives a summary of the investment costs, operating cost, revenues computed and assumptions considered for systems alternatives as discussed and summarized in Table $\mathbf{3}$.

Table 3: Summary of Economic Evaluation for Waste to Use System Alternatives for both Scenarios

\begin{tabular}{|c|c|c|c|c|c|c|}
\hline Item & COMPAD & COMPAD LF & INCAD & INTEG 1 & INTEG 2 & Status Quo \\
\hline $\begin{array}{l}\text { Investment cost CoGen } \\
\text { Investment cost-BfC }\end{array}$ & $\begin{array}{l}331,588,525 \\
271,045,568\end{array}$ & $\begin{array}{l}274,426,546 \\
217,919,786\end{array}$ & $\begin{array}{l}364,709,809 \\
304,166,852\end{array}$ & $\begin{array}{l}359,684,710 \\
279,158,282\end{array}$ & $\begin{array}{l}558,602,272 \\
445,279,159\end{array}$ & $5,443,998$ \\
\hline $\begin{array}{l}\text { Project Financing } \\
\text { Equity Capital Loan }\end{array}$ & $\begin{array}{l}30 \% \\
70 \%\end{array}$ & $\begin{array}{l}30 \% \\
70 \%\end{array}$ & $\begin{array}{l}30 \% \\
70 \%\end{array}$ & $\begin{array}{l}30 \% \\
70 \%\end{array}$ & $\begin{array}{l}30 \% \\
70 \%\end{array}$ & \\
\hline $\begin{array}{l}\text { Loan Assumptions } \\
\text { Interest rate } \\
\text { Payback period } \\
\text { Grace period }\end{array}$ & $\begin{array}{c}10 \% \\
10 \text { years } \\
1 \text { year }\end{array}$ & $\begin{array}{c}10 \% \\
10 \text { years } \\
1 \text { year }\end{array}$ & $\begin{array}{c}10 \% \\
10 \text { years } \\
1 \text { year }\end{array}$ & $\begin{array}{c}10 \% \\
10 \text { years } \\
1 \text { year }\end{array}$ & $\begin{array}{c}10 \% \\
10 \text { years } \\
1 \text { year }\end{array}$ & \\
\hline $\begin{array}{l}\text { Revenues CoGen } \\
\text { Revenues BfC }\end{array}$ & $\begin{array}{l}206,315,085 \\
149,811,942\end{array}$ & $\begin{array}{l}203,436,468 \\
146,933,325\end{array}$ & $\begin{array}{l}196,044,572 \\
139,541,429\end{array}$ & $\begin{array}{l}239,965,586 \\
164,813,206\end{array}$ & $\begin{array}{l}369,430,392 \\
263,668,780\end{array}$ & $7,424,132$ \\
\hline $\begin{array}{c}\text { Total operating costs (TOC) } \\
\text { TOC-CoGen TOC-BfC }\end{array}$ & $\begin{array}{l}133,287,445 \\
108,231,462\end{array}$ & $\begin{array}{l}115,300,097 \\
90,935,656\end{array}$ & $\begin{array}{l}140,923,224 \\
115,867,240\end{array}$ & $\begin{array}{l}153,634,864 \\
120,308,628\end{array}$ & $\begin{array}{l}194,364,142 \\
147,464,847\end{array}$ & $3,145,307$ \\
\hline $\begin{array}{l}\text { Annual income } \\
\text { Income-CoGen } \\
\text { Income-BfC }\end{array}$ & $\begin{array}{l}73,027,641 \\
41,580,481\end{array}$ & $\begin{array}{l}88,135,378 \\
55,996,677\end{array}$ & $\begin{array}{l}54,121,348 \\
22,674,189\end{array}$ & $\begin{array}{l}86,330,722 \\
44,504,578\end{array}$ & $\begin{array}{l}175,066,250 \\
116,203,934\end{array}$ & $4,278,825$ \\
\hline
\end{tabular}


Following the findings obtained and summarized in the graphs and tables, the authors were interested in further checking the robustness of the results. This was carried out by developing various scenarios especially with regards to the assumptions considered. As such, a sensitivity analysis was carried out as discussed in the next section.

\subsection{Sensitivity Analysis}

The sensitivity analysis was carried out so as to appreciate how the Integrated Waste to Use systems would perform when adjustments to the assumptions were considered. Adjustments were made to the interest rate, percentage of equity capital considered and estimated biogas losses from the anaerobic digestion units forming at least 3 scenarios. Moreover, the focus was drawn to the CoGen scenario since the much better performance was registered for all system alternatives in comparison to when the $\mathbf{B f C}$ scenario. The adjustments to the mentioned parameters included;

- Stepwise reduction of fugitive emissions from the anaerobic digestion unit to $5 \%$ and later to $3 \%$ instead of $7 \%$ initially considered. The stepwise adjustment in fugitive emissions was based on documented experiences which have indicated that optimizing biogas systems, especially in European countries could result in much lower emissions i.e. 3-10\% [52,53].

- Also, adjustment of the interest rate from $10 \%$ to $12 \%$ was considered. In developing countries like Uganda, $12 \%$ is used conventionally to annualize capital payments [54].

- A $5 \%$ discount rate instead of $10 \%$ was considered based on the assumption that other credible financial institutions interested in investing in renewable energy technologies such as Uganda Development Bank would give favorable interest rates on loans in a bid to support technology dissemination.

- Finally, a stepwise variation of equity capital for investment from $30 \%$ (base case) to $20 \%$ (worst case) and finally $40 \%$ ( best case) was considered. The stepwise consideration of equity capital was influenced by UCU's urgent need to transition from dependence on traditional biomass for cooking to cleaner energy. Hence the interest in installing any of the integrated Waste to Use systems would be enticing, prompting additional investment from the Institution [33].

The key finding from the sensitivity analysis showed that reduction of fugitive emissions from the anaerobic digestion unit to $5 \%$ and later 3\% positively influenced the NPV, PBP and IRR for all five alternatives. Specifically, the NPVs of the system alternatives increased by at least $7 \%$ in comparison to when the base case scenario was considered as shown in Fig. 9.

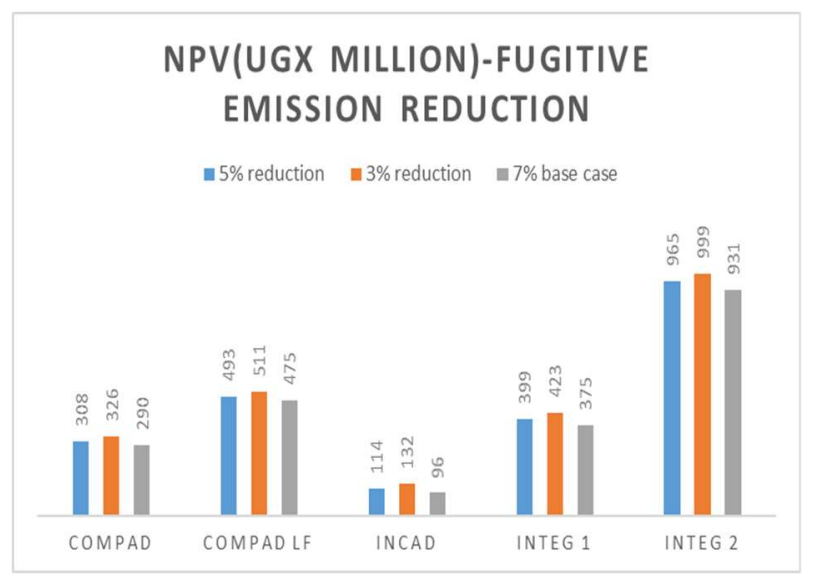

Figure 9: NPV when fugitive emissions varied.

Meanwhile, the PBP reduced by up to 1 month and an increment of $2 \%$ in IRR was registered for all the system alternatives. Generally, the much better findings registered when this scenario was considered were hinged to the 
fact that reduction of fugitive emissions implied that more biogas was available for cogeneration, increasing the electricity and heat generated and the revenue accrued. anaerobic digestion unit.

Also, when the interest rate was adjusted to $12 \%$ while the equity capital and fugitive emissions from the biogas digester were maintained at base case scenario values of 30\% and $7 \%$ respectively, results indicated there was a reduction in NPVs for certain system alternatives. The INCAD system registered a negative NPV while a reduction of up to $\mathbf{2 7} \%$ in the NPV for the COMPAD, COMPAD LF, INTEG 1 and INTEG 2 systems were registered. The performance trend still indicated that the INTEG 2 system performed best followed by the COMPAD LF, INTEG 1 and finally the COMPAD alternative. Meanwhile, when PBP and IRR, parameters were considered, the COMPAD LF system performed better than all other alternatives with an IRR of 30\% and PBP of 3.3 years followed closely by the INTEG 2 system with IRR of $29 \%$ and PBP of 3.4 years. Similar to the results from the base case scenario, additional revenue accrued due to the sale of more by-products contributed to improved NPV of INTEG 2 even though a higher interest rate was considered. While the reduced investment costs due to the use of existing infrastructure especially for the COMPAD LF scenario contributed to its good performance. Adjusting the interest rate to 5\% resulted in much higher NPVs, much lower PBPs and slightly higher IRR values for all system alternatives considered when the results were compared with the base case scenario.

Meanwhile, reducing the equity capital to 20\% resulted in reduced NPVs, increased PBPs and much lower IRR values. Alternatively, increasing the equity capital to $40 \%$ as would be expected resulted in a significant increase in NPVs by at least $100 \%$. In this case, the PBP was much lower i.e. upto a period of 1 year while, higher IRR values by at least $6 \%$ in comparison to the base case scenario, were registered. Worthy of mention is that under these conditions, the INCAD system also registered a positive NPV.

A final adjustment where equity capital was considered indicated that only the INTEG 2 and COMPAD LF systems were feasible since both systems registered positive NPVs and PBPs below 10 years, while the IRR values were at least 15\%. Given that for the INTEG 2 alternative, additional by-products from the system were expected, it is no doubt that even with no equity capital considered, the NPV was positive. Meanwhile, for the COMPAD LF system, the positive NPV was attributed to the limited investment costs given that the system design considered the use of an existing composting unit at Mukono landfill. The results also showed that the COMPAD, INCAD and INTEG 1 alternatives all registered negative NPVS, IRR values of less than $10 \%$ and PBPs ranging from 9.6 years to 18.6 years. Fig 10 shows the variation in the NPV results when the equity capital contribution was considered.

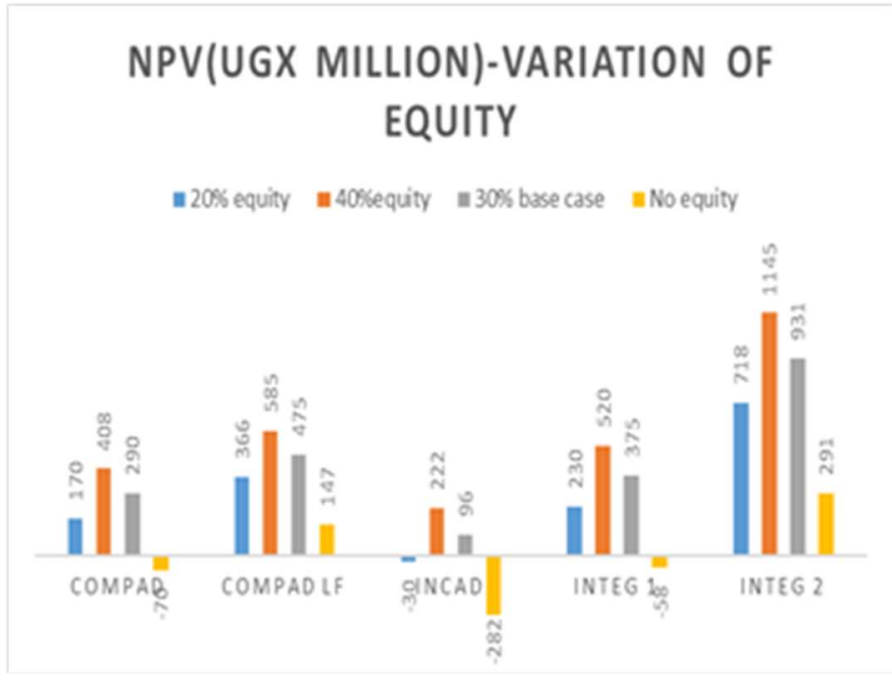

Figure 10: NPV when equity capital was varied.

Therefore, the results from the sensitivity analysis highlighted key aspects that should be critically catered for in the case of implementation of economically sustainable integrated Waste to Use systems. In the event the biogas produced is used for cogeneration, resulting in electricity and heat, then equity capital of at least 30\%, an 
interest rate less than $10 \%$ and fugitive emissions less than $7 \%$ would guarantee economic feasibility of the Integrated waste to use the system.

\section{Conclusions}

Cognizant of the challenge faced in managing waste and sanitation in urban areas of Uganda, integrated Waste to Use systems reconsidered a viable solution. Despite some of these systems being already in the application, this study focused on integrated waste to use systems that promote resource recovery through a combination of processes and technologies such as anaerobic digestion, composting, incineration and use of solar dying. As such, this study focused on assessing the economic feasibility of six proposed systems using cost-benefit analysis, taking into consideration three parameters i.e. net present value (NPV), payback period (PBP) and internal rate of return (IRR) of the systems. Results from the assessment indicated that the feasibility of the Integrated waste to use system alternatives was positively influenced by the inclusion of the anaerobic digestion unit, which allowed for resource recovery from system alternatives in form of biogas, organic fertilizer, briquettes etc.

Generally, a combination of low system investment costs and increased revenues from resource recovery positively influenced the good performance of the system alternatives. Specifically, high NPVs of up to UGX 931 million, low PBPs of up to 3.1 years and IRRs of about 30\% were registered for systems that considered additional resource recovery and use of existing infrastructure such as composting plants i.e the INTEG $\mathbf{2}$ and COMPAD LF alternatives respectively. The good performance of the Status Quo alternative which basically reflected the current situation at the University with regards to the IRR of up to 79\% and PBP of just 1.3 years was mainly attributed to low investment costs associated with the system in terms of infrastructure even though resource recovery was much less than other alternatives.

To check the robustness of the results, a sensitivity analysis was carried out, making adjustments to the assumptions initially taken. The sensitivity analysis also highlighted that for the economic feasibility of the integrated waste to use system alternatives, the equity capital of at least at least $30 \%$, an interest rate less than $10 \%$ and fugitive emissions from the biogas digester of less than $7 \%$ should be considered. Adjustment of the assumptions further emphasized that contribution of additional resource recovery from a particular system and reduced investment costs due to the use of existing units such as composting units positively influenced the feasibility of the systems, resulting in NPVs of up to UGX 1,145 million, shorter PBPs i.e. less than 10years return on investment could be obtained.

Thus, from the results, it was deduced that resource recovery informs of biogas, organic fertilizer and fuels i.e. briquettes from the proposed Waste to Use systems positively influenced the economic feasibility of the systems. Additionally, the systems allowed for combined management of organic waste streams making them attractive for urban areas in Uganda since they offer dual benefits. Even though the systems were proposed for UCU, consideration of context-specific modifications while meeting the criteria initially cited i.e. demand for environmental sanitation services focused on the management of organic waste streams, presence of an existing dependent population size of at least 1,000 people, the existence of stakeholder groups along the organic waste management value chain would be crucial in enabling application of the systems for other entities such as households, institutions of learning/health centres, industries, cities and towns

From the results obtained in this study, it would suffice to say that for developing countries like Uganda where population increase will inevitably influence urbanization, integrated Waste to Use systems that have a dual objective of sanitation improvement and resource recovery could be viable solutions. The systems additionally improve environmental conditions and public health by reduction of greenhouse gas emissions and averting poor health due to proper management of the organic waste streams. Also, from resource recovery, job creation along the value chain can be guaranteed. The systems promote a sanitation-energy-agriculture nexus, which becomes extremely attractive for urban areas where the demand for all these basic needs is continuously increasing given the population explosion. Moreover, the integrated Waste to Use systems can be easily modified to fit key interests of specific entities i.e. if incineration of waste streams is preferred or other technologies/processes like composting are preferred. 
In conclusion, the integrated Waste to Use systems suggested in this paper are economically feasible and could also constitute part of the solution to organic waste management challenges in urban areas of Uganda and other Sub-Saharan countries with similar contexts.

\section{Acknowledgment}

The authors gratefully acknowledge the financial support from Schlumburger Faculty for the Future foundation for funding this research and Uganda Christian University for the assistance accorded.

\section{References}

[1] Bank, World. What A Waste: A Global Review of Solid Waste Management. Washington: World Bank, 2012.

[2] Biogas, Fachverband. Biowaste to Biogas; Biogas Know How 1. s.I.: German Biogas Association, 2017.

[3] NEMA. Annual Performance Report 2016/2017. Kampala: National Environment Management Authority(NEMA), 2017.

[4] IFC and KCCA. Preliminary Information Memorandum, Kampala Waste PPP Project; Innovation shaping waste management in Uganda. Kampala: International Finance Corporation(IFC) and Kampala Capital City Authority(KCCA), 2020.

[5] Sippel, Lilli. Africa's demographic challenges;How a young population can make development possible. Berlin: Berlin Institute for Population and Development, 2011. 978-3-9814679-0-1.

[6] MoWE. Water and Environment Sector Performance Report 2017. Kampala: Ministry of Water and Environment(MoWE), Government of Uganda, 2017.

[7] Ministry of Water and Environment;Water and Environment Sector Performance Report. Kampala: M, 2020.

[8] Cleland, John and Machiyama, Kazuyo.The Challenges Posed by Demographic Change in sub-Saharan Africa;A Concise Overview. 2, s.I. Population and Development Review, 2017, Vol. 43. https://doi.org/10.1111/padr.170

[9] KCCA, and IFC. Project Teaser:Kampala Waste Treatment and Disposal PPP. Kampala: Kampala Capital City Authority(KCCA) and International Finance Authority(IFA), 2017.

[10] Independent, The. The Independent. [Online] 2020. [Cited: June 13, 2021.] https://www.independent.co.ug/mbale-city-chokes-onuncollected-garbage-stench/.

[11] Gumisiriza P, Kugonza S.Corruption and Solid Waste Management in Mbarara Municipality, Uganda. 2020, Journal of Environmental and Public Health, Vol. Volume 2020, pp. 2-9. https://doi.org/10.1155/2020/4754780

[12] Oates L, et al. Supporting decent livelihoods through sustainable service provision: Lessons on solid waste management from Kampala, Uganda. s.l.: UKaid, 2019.

[13] GGGI. Kampala Municipal Solid Waste Value Chain Mapping. Kamapla: Global Green Growth Institute(GGGI), 2018.

[14] Parkinson J, Lüthi C, Walther D. Sanitation 21: A planning Framework for Improving City-Wide Sanitation Services. s.I.: IWA, EAWAG, GIZ, SuSana, 2014.

[15] Andersson K, et al. Sanitation Wastewater Management and Susutainability:From Waste Disposal to Resource Recovery. s.l.: United Nations Environment Programme and Stockholm Environment Institute., 2016.

[16] WELL. Guidance manual on water supply and sanitation programmes. London: Water \& Environmental Health at London and Lougborough, funded by DFID, 1998.

[17] WSSCC and WHO, and. Sanitation and Hygiene Promotion:Programming Guidance. s.I.: Water Supply \& Sanitation Collaborative Council:WSSCC, and World Health Organization, 2005.

[18] EAWAG-SANDEC. Household-Centred Environmental Sanitation:Implementing the Bellagio Principles in Urban Environmental Sanitation: Provisional Guideline for Decision-Makers. Dübendorf: Eawag: Swiss Federal Institute of Aquatic Science and Technology, 2005. 3-906484-35-1.

[19] Luithi C, et al. Rethinking sustainable Sanitation for the Urban Environment. 2009.

[20] UNICEF. Generating Energy with Biogas Latrines in Schools in Uganda. s.I.: United Nations International Children's Emergency Fund, 2014.

[21] Agunyo MF, et al.Exploring the Environmental Feasibility of Integrated Sanitation Systems for Uganda. 2018, Journal of Sustainable Development of Energy, Water and Environment Systems. https://doi.org/10.13044/j.sdewes.d6.0217

[22] Agunyo MF, Bacwayo KE, Kizza-Nkambwe S. Assessment of the socio-cultural viability of integrated waste-to-energy systems for Uganda. 3, 2020, Int. J. Renewable Energy Technology, Vol. 11, pp. 272-294. https://doi.org/10.1504/IJRET.2020.112009

[23] Parkes O, Lettieri P, Bogle DL. Life cycle assessment of integrated waste management systems for alternative legacy . s.l.: Waste management (New York, N.Y.), 2015, Vol. 40. https://doi.org/10.1016/j.wasman.2015.03.017

[24] Chiu, Sam LH, et al. Life cycle assessment of waste treatment strategy for sewage sludge and food waste in Macau:Perspectives on environmental and energy production performance. 2, s.l.: Int J Life Cycle Assess (The International Journal of Life , 2016, Vol. 21. https://doi.org/10.1007/s11367-015-1008-2 
[25] TBC. Sanitation in the Circular Economy:Transformation to a commercially valuable, self-sustaining, biological system. s.l.: Toilet Board Coalition, 2016.

[26] WSP. Economic Impacts of Sanitation in Southeast Asia:A four-country study conducted in Cambodia, Indonesia, the Philippines and Vietnam under the Economics of Sanitation Initiative (ESI). s.I.: Water and Sanitation Program, World Bank Group, 2008.

[27] McIntyre P, et al. Priceless! Uncovering the real costs of water and sanitation. s.I.: IRC International Water and Sanitation Centre, 2014. 978-90-6687-082-6.

[28] WSP. Lessons in Urban Sanitation Development:Indonesia Sanitation Sector Development Program 2006-2010. s.I.: Water and Sanitation Program, 2011.

[29] Hutton G. Water and Sanitation Assessment Paper:Benefits and Costs of the Water Sanitation and Hygiene Targets for the Post-2015 Development . s.l.: World Bank, 2015.

[30] Brent RJ. Applied Cost-Benefit_Analysis. s.l.: Edward Elgar Publishing Limited, 2006. 9781843768913.

[31] Yiridoe EK, Gordon R, Brown BB. Nonmarket cobenefits and economic feasibility of on-farm biogas energy production. 3, s.I.: Energy Policy, 2009, Vol. 37. https://doi.org/10.1016/j.enpol.2008.11.018

[32] Yin RK. Case study research:Design and methods. Los Angeles: SAGE, 2014. 978-1-4522-4256-9.

[33] UCU. Uganda Christian University Strategic Plan 2012-2018. s.l.: Uganda Christian University, 2012.

[34] Kanathigoda A. Faecal Sludge Manangement in Kampala and smaller urban areas. 2014.

[35] Karellas S, Boukis I, Kontopoulos G. Development of an investment decision tool for biogas production from agricultural waste. s.l.: Renewable and Sustainable Energy Reviews, 2010, Vol. 14. 10.1016/j.rser.2009.12.002. https://doi.org/10.1016/j.rser.2009.12.002

[36] Antaleo A, Gennaro BD, Shah N. Assessment of optimal size of anaerobic co-digestion plants:An application to cattle farms in the province of Bari (Italy). P. s.l.: Renewable and Sustainable Energy Reviews, 2013, Vol. 20. 10.1016/j.rser.2012.11.068. https://doi.org/10.1016/j.rser.2012.11.068

[37] Otoo M, Rao K, Taron A. Synthesis Report on Feasibility Assessment for the Implementation of RRR business models proposed for Lima. s.I.: Swiss Agency for Development and Corporation:SDC, 2015.

[38] Ackerman F. Critique of cost-benefit analysis and alternative approaches to decision-making:A report to Friends of the Earth England, Wales and Northern Ireland. 2008.

[39] Weimer DL. Cost Benefit Analysis and Public Policy. s.l.: Journal of Policy Analysis and Management Classics Series, 2008. https://doi.org/10.1002/9781444307177

[40] Hutton G, Haller L. Evaluation of the Costs and Benefits of Water and Sanitation Improvements at the Global. s.I.: World Health Organisation:WHO, 2004.

[41] Hutton G, Haller L, Bartram J. Global cost-benefit analysis of water supply and sanitation interventions.. 4, s.I.: Journal of water and health, 2007, Vol. 5. 10.2166/wh.2007.009. https://doi.org/10.2166/wh.2007.009

[42] Deeks LK, et al. A new sludge-derived organo-mineral fertilizer gives similar crop yields as conventional fertilizers. s.I.: Agron. Sustain. Dev. (Agronomy for Sustainable Development), 2013, Vol. 33. 10.1007/s13593-013-0135-z. https://doi.org/10.1007/s13593-013-0135-z

[43] Kahiluoto $\mathrm{H}$, et al. Phosphorus in manure and sewage sludge more recyclable than in soluble inorganic fertilizer.. 4, s.I.: Environ. Sci. Technol. (Environmental Science \& Technology), 2015, Vol. 49. 10.1021/es503387y. https://doi.org/10.1021/es503387y

[44] Drosg B, et al. Nutrient Recovery by Biogas Digestate Processing. s.l.: IEA Bioenergy, 2015.

[45] Al Seadi T, et al. Biogas Handbook. Esbjerg: University of Southern Denmark Esbjerg, 2008. 978-87-992962-0-0.

[46] Raheem A, et al.Opportunities and challenges in sustainable treatment and resource reuse of sewage sludge: A review. s.l.: Chemical Engineering Journal, 2018, Vol. 337. 10.1016/j.cej.2017.12.149. https://doi.org/10.1016/j.cej.2017.12.149

[47] Evans TD. Review of Current Knowledge: Sewage Sludge. s.l.: Foundation for Water Reseach , 2016.

[48] Vögeli Y, et al. Anaerobic digestion of biowaste in developing countries. Dübendorf: s.n., 2014.

[49] Walla C, Schneeberger W. The optimal size for biogas plants. 6, s.l.: Biomass and Bioenergy, 2008 , Vol. 32. 10.1016/j.biombioe.2007.11.009. https://doi.org/10.1016/j.biombioe.2007.11.009

[50] FEA. Technical Guide on the Treatment and Recycling Techniques for Sludge from municipal Wastewater Treatment with references to Best Available Techniques (BAT). s.I.: Federal Environment Agency: (Umwelt Bundesamt), 2014.

[51] GIZ. Biogas Technology Matrix. s.l.: Deutsche Gesellschaft für Internationale Zusammenarbeit, 2016.

[52] Jonerholm K, Lundborg H. Methane losses in the biogas system. 2012.

[53] Jørgensen L, Kvist T. Methane emission from Danish biogas plants. 2015.

[54] Walekhwa PN, Lars D, Mugisha J. Economic viability of biogas energy production from family-sized digesters in Uganda. s.I.: Biomass and Bioenergy, 2014, Vol. 70. 10.1016/j.biombioe.2014.03.008. https://doi.org/10.1016/j.biombioe.2014.03.008

[55] MoWE. Water and Environment Sector Performance Report. Kampala: Ministry of Water and Environment, 2020.

[56] MoWE, Water and Environment Sector Performance Report. Kampala: 2020. 